\title{
O Ensino de Climatologia como Componente Curricular no Ensino Fundamental: Estudo de Caso em Escolas Públicas da Rede Municipal de Maracanaú/Ce
}

\author{
Maria Leorne Aguiar Araújo ${ }^{1}$ (D), Roberto José Almeida De Pontes ${ }^{1}$, \\ Emerson Mariano da Silva ${ }^{1}$ \\ ${ }^{1}$ Mestrado Profissional em Climatologia e Aplicações nos Países da CPLP e África, Universidade \\ Estadual do Ceará, Fortaleza, CE, Brazil.
}

Recebido em: 2 de Junho de 2021 - Aceito em: 1 de Dezembro de 2021

\begin{abstract}
Resumo
O estudo investigou as concepções de estudantes e professores de três escolas públicas do munícipio de Maracanaú no Ceará sobre a importância dos conteúdos ministrados e as práticas pedagógicas usadas nas aulas de climatologia no ensino fundamental. A pesquisa foi realizada através da aplicação de questionários estruturados. Os resultados obtidos foram analisados usando estatística descritiva (distribuição de frequência) e discutidos usando-se reflexões teóricas sobre a aplicação de metodologias ativas em sala de aula. Assim, concordando com estudos publicados sobre essa temática, os resultados encontrados evidenciam a importância da ministração desses conteúdos através de práticas pedagógicas inovadoras e de atividades interdisciplinares que possam contribuir positivamente com processo de ensinoaprendizagem dos conteúdos ministrados nas aulas de climatologia.
\end{abstract}

Palavras-chave: climatologia, metodologias ativas, ensino-aprendizagem.

\section{Climate Teaching as a Curriculum Component in Elementary Education}

\begin{abstract}
The study investigated the conceptions of students and teachers from three public schools in the municipality of Maracanaú in Ceará about the importance of the contents taught and the pedagogical practices used in climatology classes in elementary school. The research was carried out through the application of structured questionnaires. The results obtained were analyzed using descriptive statistics (frequency distribution) and discussed using theoretical reflections on the application of active methodologies in the classroom. Thus, in agreement with published studies on this topic, the results found show the importance of providing these contents through innovative pedagogical practices and interdisciplinary activities that can positively contribute to the teaching-learning process of the contents taught in climatology classes.
\end{abstract}

Keywords: climatology, active methodologies, teaching-learning.

\section{Introdução}

As aulas de climatologia no ensino médio possibilitam ao estudante compreender os fenômenos atmosféricos, as questões relativas à circulação geral da atmosfera, bem como a variabilidade climática observada em uma determinada região.

No caso em questão, o estudo teve recorte geográfico o município de Maracanaú no Ceará, região semiárida do nordeste brasileiro. Assim, as aulas de climatologia podem oportunizar além dos conhecimentos gerais sobre a composição da atmosfera, o conhecimento da variabilidade climática local e regional, podem ser trabalhados em sala de aula fenômenos como as secas e as enchentes, associadas à condição da quadra chuvosa observada na região.

Dessa forma pode-se apresentar aos estudantes a possibilidade de compreende-se a relevância da variabilidade e das mudanças climáticas, além de apresentar a influência destes fenômenos (naturais ou extremos) nas atividades cotidianas e nos setores de interesses econômi$\cos$ da região. E, incentivar o estudante a efetivar os conhecimentos específicos sobre as variáveis meteorológicas, favorecendo a compreensão de interações em

Autor de correspondência: Maria Leorne Aguiar Araújo, marialeorne@gmail.com. 
diferentes escalas espaciais e temporais, comparando-as e conferindo-lhes significados de acordo ao contexto no qual está inserido.

É de fundamental importância nesse processo de ensino-aprendizagem a figura do professor e as suas práticas em sala de aula, pois a aplicação de novas possibilidades pedagógicas, como as metodologias ativas, pode motivar os estudos, pesquisas e reflexões de temas com focos específicos como o estudo da climatologia local, de acordo com os componentes curriculares (Parâmetros Curriculares Nacionais e Base Nacional Curricular Comum) do ensino fundamental.

À medida que o professor coloca em prática a mediação pedagógica, instigando os estudantes a identificar os problemas e a buscar resoluções com autonomia, de formas assertiva e criativa, através do uso de metodologias ativas, se tem a possibilidade do desenvolvimento de competências e habilidades para compreenderem a dinâmica climática, e assim, serem capazes de refletir e entender as relações entre a sociedade e o clima, as variabilidades climáticas e as mudanças climáticas observadas nesta região.

Neste contexto, o objetivo deste estudo é investigar o uso das metodologias ativas nas aulas de climatologia. Dessa forma, foram aplicados questionários estruturados, aprovados pela pelo Comitê de Ética em Pesquisa (CEP) da Plataforma Brasil, a estudantes e professores em três escolas do ensino fundamental da rede pública municipal de Maracanaú no Ceará.

Em específico, o estudo objetiva além de diagnosticas as práticas pedagógicas nas aulas de climatologia, promover uma reflexão sobre o uso de práticas pedagógicas inovadoras (ativas) que possibilitem o desenvolvimento da capacidade investigativa dos estudantes nesta área do conhecimento.

\section{Os Conteúdos de Climatologia como Componente Curricular no Ensino Fundamental}

$\mathrm{O}$ estudo de temas que correspondem ao ensino de climatologia possui grande relevância na medida em que contribui na explicação de fenômenos que fazem parte do cotidiano dos estudantes, tais como a ocorrência de chuvas intensas que podem causar desastres naturais como as inundações e os alagamentos.

Ao ter conhecimento dos fenômenos climáticos é possível identificar a importância do clima na vida e nas atividades cotidianas. Por exemplo, no período chuvoso da porção norte da região semiárida do nordeste brasileiro, especificamente no Estado do Ceará, que compreende o período entre os meses de fevereiro a maio (Alves e Repelli, 1992), se tem maior atenção ao tempo meteorológico antes da realização de algumas atividades, como se deslocar pelas ruas das cidades dessa região, pois pode-se observar chuvas intensas e até classificadas como torren- ciais que causam inundações e alagamentos na região (Silva et al. 2019).

Assim, no ensino dos conteúdos de climatologia na escola fundamental considera-se necessário enfatizar a dinâmica do clima no contexto urbano das cidades, em especial a ênfase nas regiões que observam chuvas intensas e, com isso, alagamentos, inundações e deslizamentos de encostas.

Outro ponto importante a ser trabalhado em sala de aula e a variabilidade da temperatura do ar (máxima, mínima e média), como ênfase em períodos de ocorrências de altas temperaturas, que associados a baixos índices de umidade relativa do ar, podem causar além de desconforto térmico, o aumento da ocorrência das doenças respiratórias.

Desta forma, trazer questões pertinentes que associam os conteúdos ministrados nas aulas de climatologia com as situações cotidianas dos estudantes ou em lugares próximos realidade, possibilita promover aprendizagens significativas que influenciam de forma positiva na dinâmica do processo de ensino-aprendizagem

A ministrações desses conteúdos estão de acordo com as orientações contidas nos Parâmetros Curriculares Nacionais (PCNs) e Base Nacional Comum Curricular (BNCC): "descrever os movimentos do planeta e sua relação com a circulação geral da atmosfera, o tempo atmosférico e padrões climáticos, sendo analisados como processos dinâmicos que não ocorrem de forma isolada, mas em interação com outros fenômenos naturais" (BNCC, 2017) e corroboram com o descrito por Ayoade (1996), que menciona o estudo do tempo e do clima, como fenômenos naturais dinâmicos que interagem de forma complexa no espaço geográfico, como facilitador para a compreensão da relação entre a natureza e as ações humanas sobre o meio ambiente.

Estudos mais recentes evidenciam a importância do ensino de climatologia na escola fundamental para o despertar da consciência cidadã e ambiental, bem como para a identificação e prevenção de desastres naturais por parte dos estudantes (Silva et al., 2021; Almeida et al., 2020; Catanho et al., 2020; Fernandes et al., 2020).

Em Silva et al. (2021) encontra-se os resultados da aplicação de uma proposta pedagógica intitulada "No Ceará tem disso, sim!" em que foram trabalhados nas aulas de climatologia os conteúdos sobre a relação entre a ocorrência de sismos (tremores de terra) e as mudanças em uma escola pública da rede municipal de Fortaleza no Ceará.

Os autores relatam que após a ministração desses conteúdos observaram entre os estudantes a evolução do conhecimento teórico e científico, bem como a consciência coletiva para desenvolver futuras ações que visam mitigar os riscos e os efeitos dos desastres naturais desencadeados por possíveis mudanças no clima da região.

Fernandes et al. (2020) apresentaram uma proposta pedagógica que usa um aplicativo de internet (ClimaCE), 
desenvolvido pelos autores, para facilitar o processo de ensino-aprendizado dos conteúdos de climatologia ministrados para os estudantes do ensino médio. O aplicativo contém diversos conteúdos relacionados a temática, tais como a descrição dos principais sistemas meteorológicos responsáveis pelas chuvas no estado do Ceará, e curiosidades. Além de um jogo de perguntas e respostas (Quiz) com o objetivo de estabelecer interação entre os atores envolvidos no processo de ensino-aprendizado. Concluem que essa metodologia pode motivar os estudantes, propiciando discussões que contribuem para o processo formativo e para o despertar de uma consciência ambiental coletiva.

Almeida et al. (2020) avaliaram o nível de percepção dos professores do ensino fundamental da rede pública do município de General Sampaio no Ceará dos impactos das mudanças climáticas no bioma Caatinga através de uma pesquisa de campo baseada em entrevistas. Mostraram que existe uma percepção coletiva sobre a variabilidade climática observada na região, encontram entre as respostas obtidas, a descrição de sensações térmicas inconstantes, a observação de secas extremas e de chuvas fora do período chuvoso da região (eventos extremos), porém, não reconhecem entre as respostas os riscos que o bioma Caatinga e a população da região estão correndo diante da ameaça das mudanças climáticas.

Além das questões supracitadas, ressalta-se que os conteúdos ministrados nas aulas de climatologia no ensino médio podem auxiliar na compreensão da influência das variabilidades climáticas observadas em uma determinada região nas diferentes atividades econômicas, tais como na agricultura, na pecuária, nas atividades de turismo, entre outras. Assim, acredita-se que o ensino dos conteúdos nas aulas de climatologia perpassa a ideia da apresentação de conteúdos descritivos e que é possível articular métodos de ensino que possam articular estratégias didáticas, recursos tecnológicos e os conhecimentos prévios sobre a temática com o propósito de potencializar a aprendizagem dos estudantes, concordando-se com o descrito por Callai (2010).

\section{Metodologia}

O presente estudo foi baseado na aplicação de questionários estruturados, aprovados pelo Comitê de Ética em Pesquisa (CEP) da Plataforma Brasil, para cem estudantes e cinquenta professores do ensino fundamental de três escolas da rede pública municipal de Maracanaú no Estado do Ceará, selecionadas pelo Índice de Desenvolvimento da Educação Básica (IDEB) alcançados no ano de 2018 (maior, médio e menor).

Os questionários destinados à coleta de dados (baseados na escala Likert) são constituídos por uma série ordenada de perguntas que objetivou levantar opiniões, expectativas e situações vivenciadas sobre a prática meto- dológicas ativas nas aulas de climatologia. As questões foram respondidas pelos informantes sem a presença do pesquisador.

Os resultados obtidos foram analisados usando-se estatística básica (distribuição de frequência), visando obter a correspondência entre o escopo geral do estudo e as informações coletadas por meio da aplicação dos questionários. Assim, os resultados aqui apresentados e discutidos representam as respostas mais relevantes sobre a temática obtidas entre estudantes e professores colaboradores da pesquisa.

\section{Resultados e Discussões}

\section{1. Área de estudo da pesquisa: Maracanaú}

A área de estudo da pesquisa foi o município de Maracanaú (Fig. 1), no estado do Ceará, nome de origem indígena que significa, em tupi, lagoa onde as maracanãs bebem; que se relacionam à grande quantidade de aves que sobrevoavam suas lagoas no período de crescimento do povoado. Oficializado emancipado no dia 6 de março de 1983, fica localizado na Região Metropolitana de Fortaleza - RMF, a $24 \mathrm{~km}$ da capital cearense, área territorial: $106,648 \mathrm{~km}^{2}$. O censo de 2010 , do IBGE população: 209.057 habitantes, e estimativa para 2019 total de 227.886 habitantes.

Maracanaú detém o segundo maior Produto Interno Bruto - PIB do Ceará, após o de Fortaleza, e o segundo maior PIB per capita do Ceará, estando após o município de Euzébio. A escolha do município justifica-se pela sua organização administrativa; pelos avanços nos resultados do IDEB de 2017, superando os resultados das metas projetadas pelo Instituto Nacional de Estudos e Pesquisas Educacionais Anísio Teixeira (INEP), conforme mostrado na Fig. 2 .

A Rede Municipal de Ensino de Maracanaú em 2020 era composta por oitenta e uma escolas que atendem desde a Educação Infantil ao Ensino Fundamental. Dentre as oitenta e uma escolas, quarenta atendem ao Ensino Fundamental Anos Finais com o total de 13.807 estudantes do $6^{\circ}$ ao $9^{\circ}$ ano, dentre estes temos no $6^{\circ}$ ano o quantitativo de 3.297 e no $8^{\circ}$ ano 3.877. Neste universo, optou-se em realizar a pesquisa com 100 estudantes de três escolas, considerando como critério os resultados do IDEB, das escolas: A - melhor, B - médio e o C - menor índice.

$\mathrm{O}$ quadro de professores efetivos do Município apresenta: 80 em Geografia e 72 em Ciências. Contudo, a pesquisa agregou a participação de 50 professores de Geografia e de Ciências que responderam sobre a utilização das metodologias ativas no ensino da Climatologia.

\subsection{Resultados e Discussões}

A seguir, serão apresentados os resultados, considerados mais relevantes para as discussões propostas nesse 


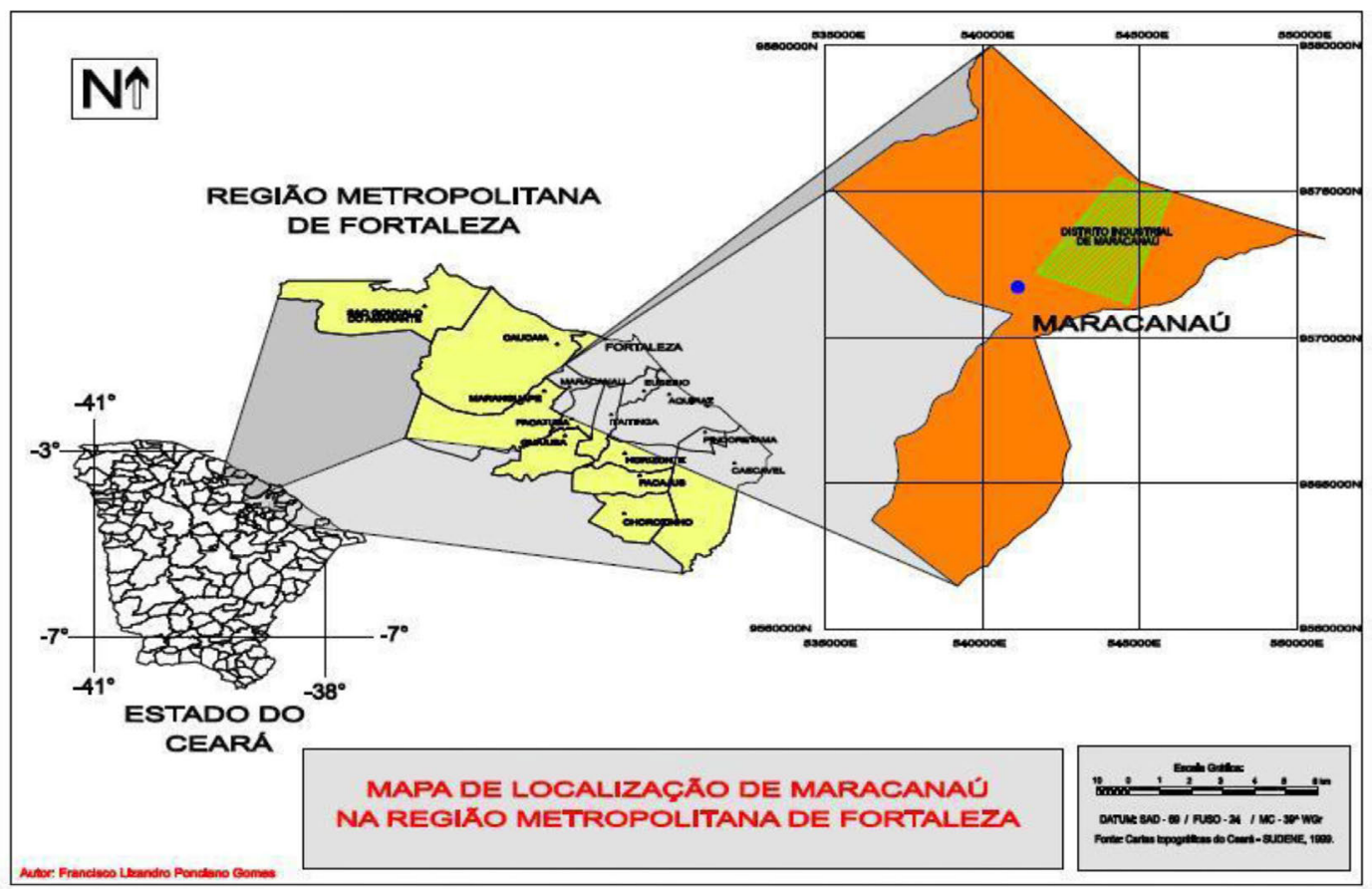

Figura 1 - Localização de Maracanaú - CE. Fonte: Adaptado de Sudene (1999) por Gomes (2010) apud Cajazeiras (2012).

Evolução do IDEB (2005 a 2017)

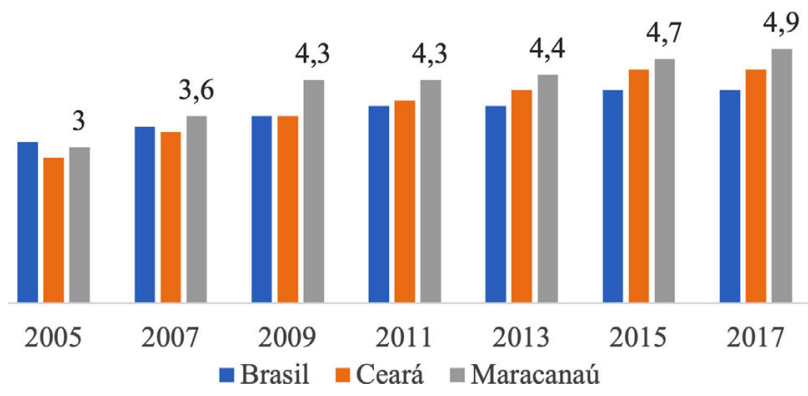

Figura 2 - Os Resultados do IDEB no Ensino Fundamental Anos Finais (2005 a 2017). Fonte: Secretaria Municipal de Educação de Maracanaú SME (2020).

estudo, obtidos com a aplicação dos questionários (professores e estudantes).

Em relação à identificação da prática pedagógica adotada por professores participantes da pesquisa (Fig. 3), constatou-se a predominância de $44 \%$ com o perfil de facilitador e $34 \%$ identificaram-se como mediador no processo de ensino-aprendizagem. Neste contexto, compreende-se que a atuação do professor mediador requer mudança de mentalidade, implica em romper paradigmas conservadores e refletir sobre a função que você pretende assumir na sua prática pedagógica.

Adiante, buscou-se identificar o grau de dificuldade dos estudantes no entendimento dos conteúdos de climatologia contidos no livro didático adotado pela escola. Assim, verificou-se que $70 \%$ dos professores afirmaram

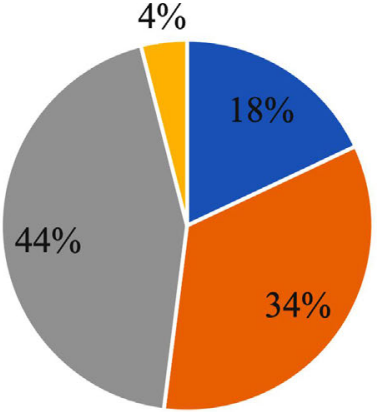

- Orientador $"$ Mediador $\|$ Facilitador $\|$ Transmissor

Figura 3 - Identificação da prática pedagógica dos professores.

que os estudantes apresentam dificuldades ao recorrerem aos conteúdos de climatologia abordados no livro didático (Fig. 4), considerando esses conteúdos como difíceis ou muito difíceis. Acredita-se que, neste caso, tem-se a necessidade de articulação entre os conteúdos a serem ministrados nas aulas de climatologia e a vivência dos estudantes e, assim, relacioná-los com outros fenômenos naturais e sociais que podem favorecer uma aprendizagem significativa.

Sobre a utilização das Tecnologias Digitais de Informação e Comunicação (TDIC) nas aulas de climatologia, detectou-se que $66 \%$ afirmam utilizar as tecnologias digitais, $34 \%$ não utilizam tais recursos. Logo, observou-se um quantitativo expressivo de professores usando essas ferramentas como suporte pedagógico visando desenvolver competências e habilidades referentes aos conteúdos 


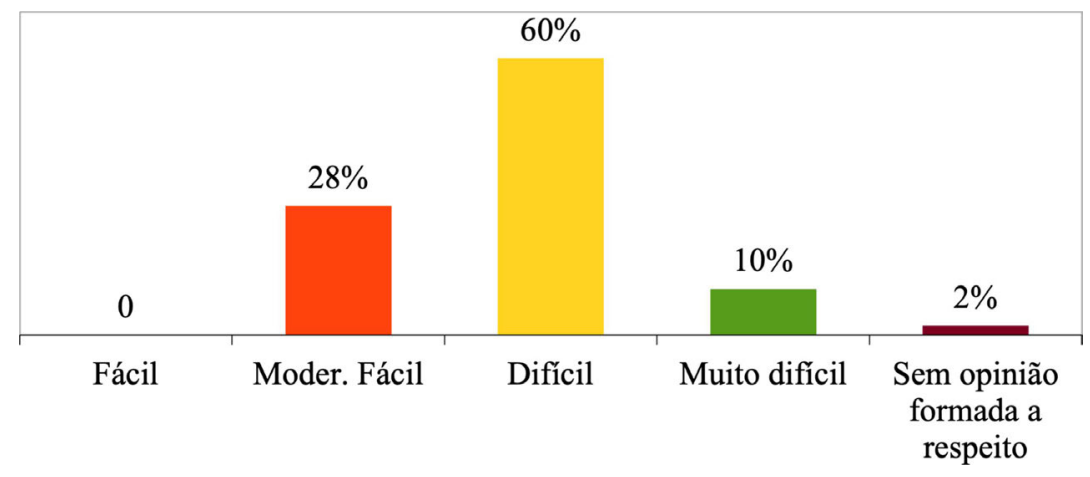

Figura 4 - Grau de dificuldade dos estudantes.

trabalhados nas aulas, em específico ao trabalhar os conteúdos ministrados referente a climatologia.

Em adição, menciona-se que se tem a afirmativa da utilização de metodologias ativas, consideradas novidades por uma parcela dos entrevistados, por $84 \%$ dos professores que conhecem estas estratégias de ensino.

Ainda em relação às metodologias ativas utilizadas pelos professores, constatou- que $34 \%$ utilizavam atividades baseadas em trabalho de equipe, uma das estratégias que possibilita potencializar o processo de aprendizagem ativa, propondo questionamentos relevantes sobre a temática em estudo e tentando solucioná-lo por meio de pesquisas em diferentes fontes, buscando argumentações confiáveis para serem discutidas entre os colegas de equipe de forma colaborativa (Fig. 5).

Quanto à frequência da utilização das metodologias ativas nas aulas de climatologia, verificou-se que as estratégias aplicadas mais citadas são, ou seja, usadas muitas vezes, são as aulas expositivas (43\%) e aprendizagem por situações concretas (36\%), pesquisas e trabalho de equipe (38\%), já as menos aplicadas (raramente) são os jogos $(45 \%)$, projetos interdisciplinares e situações concretas e desafiadoras (Fig. 6).

Sobre a relação da utilização de metodologias ativas no ensino de climatologia para alcançar os objetivos planejados, identificou-se um percentual de $52 \%$ dos professores afirmando que as metodologias ativas contribuem de modo significativo e $42 \%$ que os objetivos propostos nas aulas são atingidos de forma parcial, $6 \%$ dos professores se abstiveram de responder.

Os benefícios de se trabalhar com as metodologias ativas em sala de aula são considerados de excepcional relevância pelos entrevistados (Fig. 7), pois podem trazer resultados satisfatórios no processo de ensino-aprendizagem. Estas estratégias metodológicas podem gerar estímulos à criatividade do estudante, aprendizagem com os colegas, descoberta de potenciais, evolução como pesquisadores/pessoas, contribuição para a valorização dos conhecimentos prévios, transformando os estudantes em protagonistas de sua aprendizagem.

Quanto aos recursos usados pelos professores em sala de aula, observa-se que $29 \%$ dos estudantes responderam que o trabalho em equipe foi o mais utilizado pelo professor (Fig. 8). Este resultado suscita uma reflexão sobre a relevância do trabalho em equipe, no qual possibilita uma aprendizagem colaborativa e significativa, pois oportuniza a troca de experiência e a construção de novos saberes.

No questionamento sobre o estudo das variabilidades climáticas em sala de aula, se constatou que $94 \%$ dos respondentes já estudaram a temática no ambiente escolar. Este objeto de conhecimento requer reflexões sobre o progressivo aquecimento global do planeta e o atual cenário consumista da sociedade.

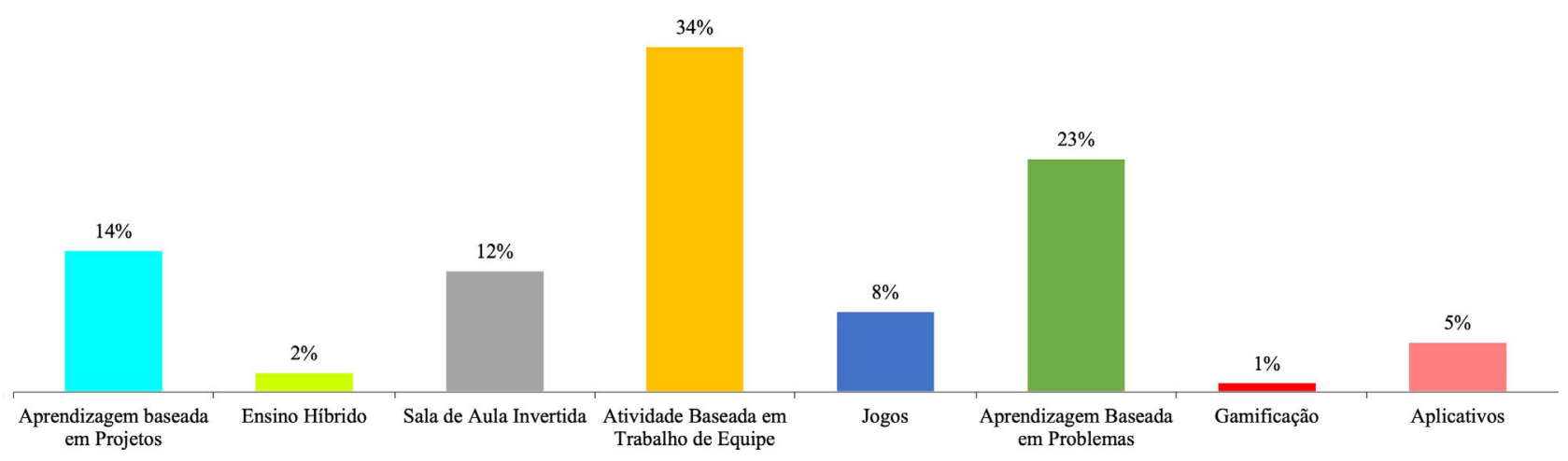

Figura 5 - As metodologias ativas utilizadas no ensino de climatologia. 


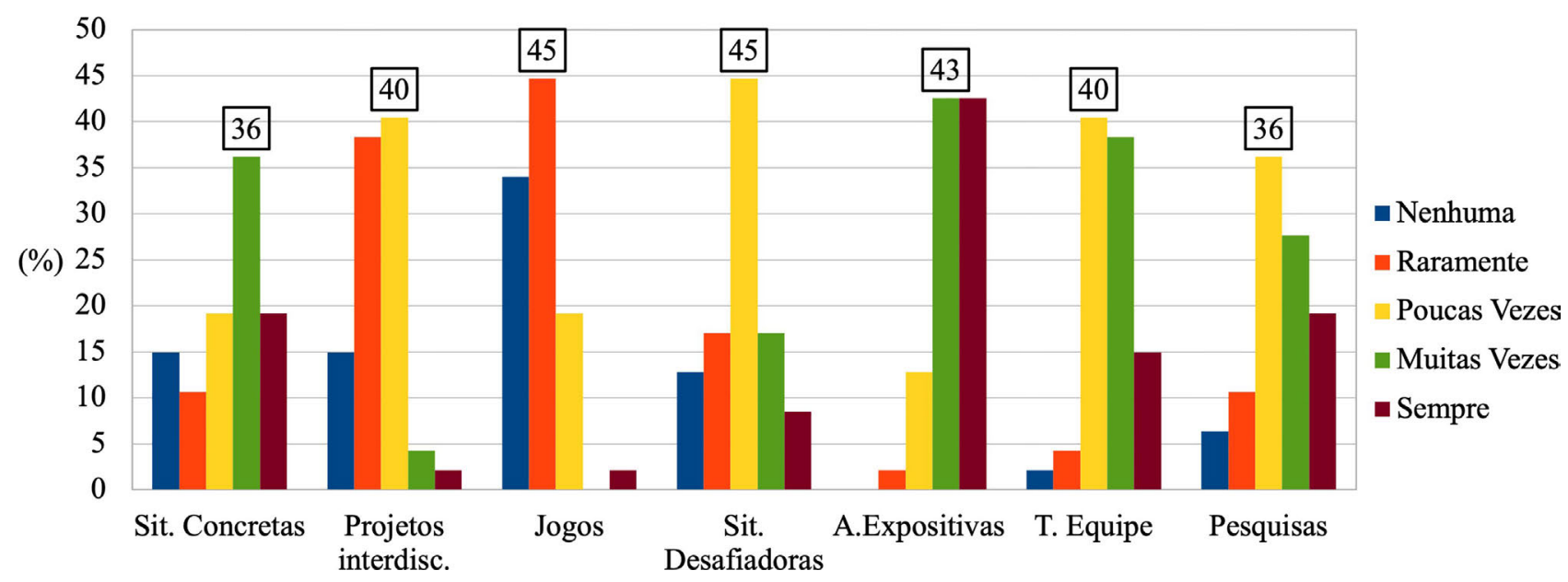

Figura 6 - Frequência da utilização das metodologias ativas nas aulas de climatologia.

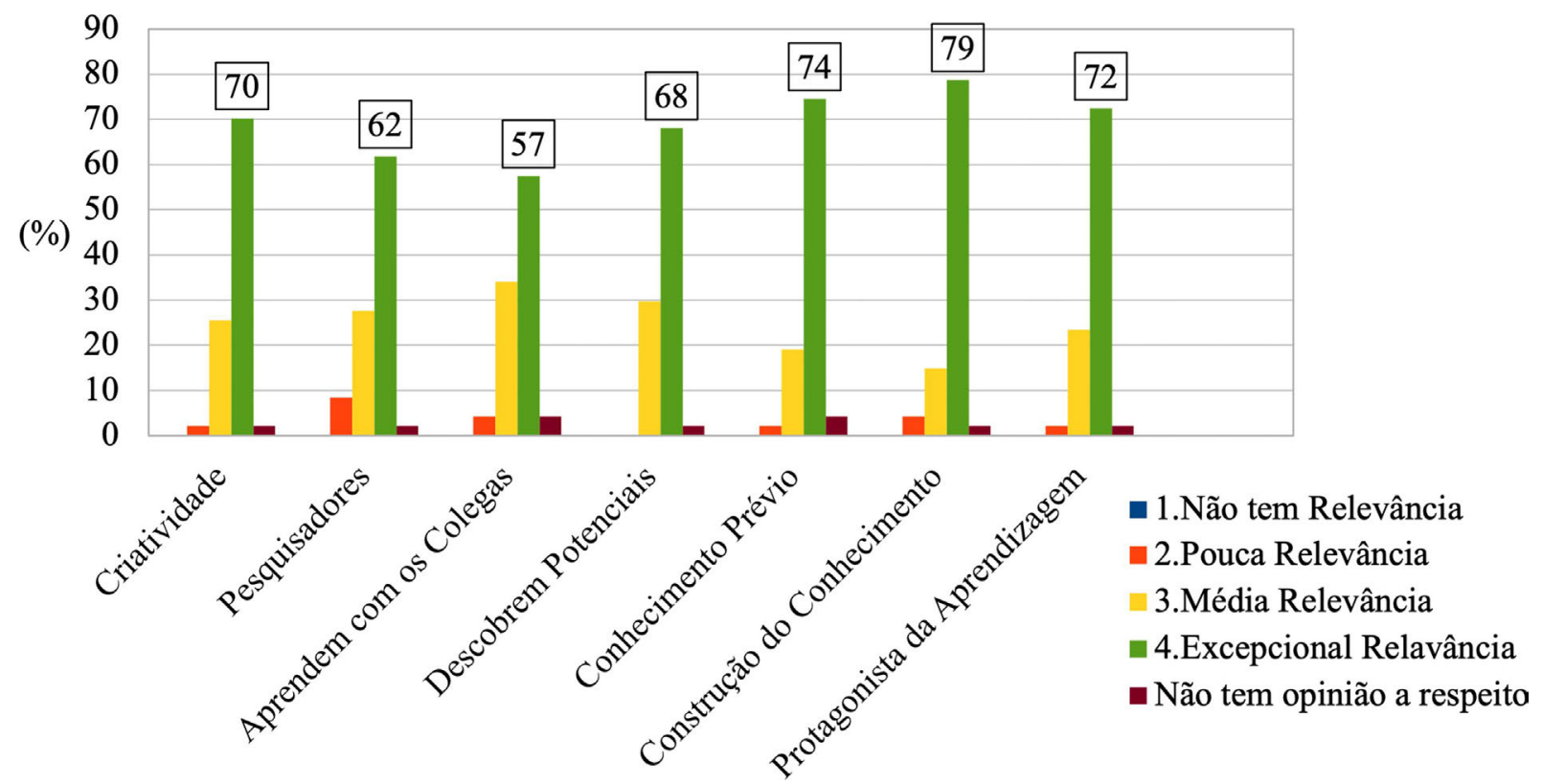

Figura 7 - Os benefícios de trabalhar com as metodologias ativas.

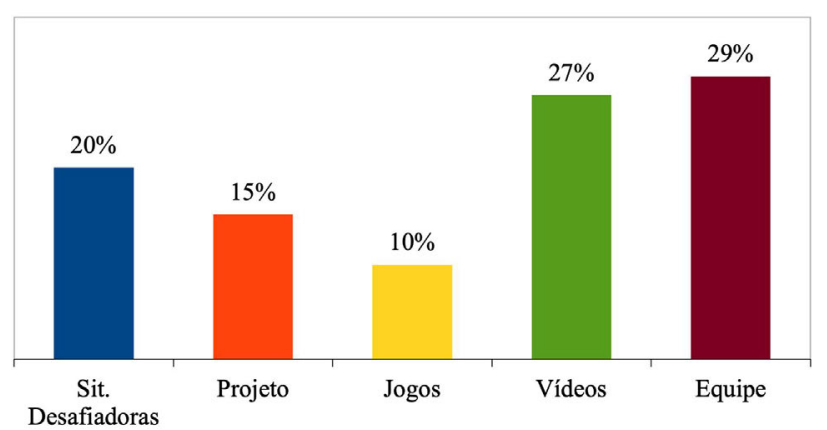

Figura 8 - Recursos didáticos usados por professores em sala de aula.

Quanto à utilização da internet pelos estudantes para realizarem suas pesquisas, observou-se um percentual de
95\% que afirmam realizar suas pesquisas pela internet, enquanto, $5 \%$ não utilizam essa ferramenta. Considera-se a internet, como um dos recursos que possibilitam investigar uma infinidade de assuntos em diversas fontes para o aprendiz desenvolver sua pesquisa com uma base teórica consistente.

Em relação a participação dos estudantes em projetos que envolve vários professores de diferentes componentes curriculares em projetos interdisciplinares, em particular em atividades que objetivam o estudo do clima nas regiões em que vivem, observou-se que $43 \%$ afirmaram que participaram dessas atividades, enquanto 57\% indicaram que não participaram de atividades (Fig. 9).

Em relação a importância da previsão do tempo, um percentual significativo de $73 \%$ dos estudantes que con- 


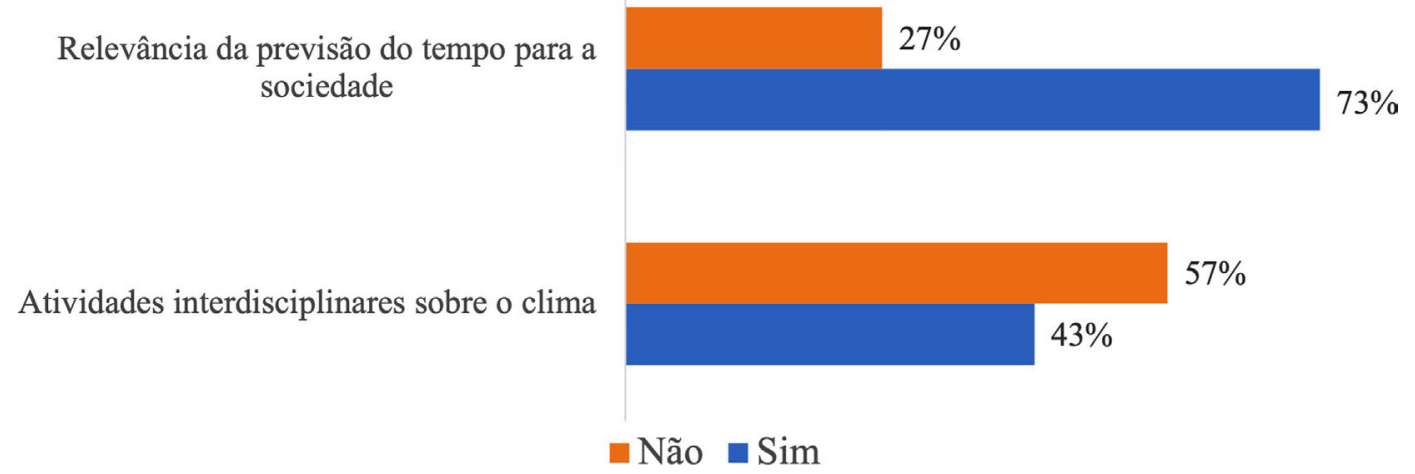

Figura 9 - Atividades sobre tempo e clima.

firmam reconhecer a relevância de acompanhar a previsão do tempo e $27 \%$ responderam que estas informações não têm importância (Fig. 9).

Assim, ressalta-se que a adoção de práticas ativas nas aulas de climatologia pode proporcionar a realização de atividades envolvendo mapas, imagens de satélites e dados referentes as variáveis do clima (temperatura e umidade relativa do ar, pressão atmosférica, vento e precipitação pluviométrica), proporcionando a análise e compreensão das variabilidades climáticas, bem como a construção do conhecimento nessa temática, concordando com os estudos supracitados (Silva et., 2021; Almeida et al., 2020; Catanho et al., 2020; Fernandes et al., 2020).

Sobre a influência da previsão do tempo nas atividades diárias, observou-se que $30 \%$ dos estudantes ficam atentos a previsão do tempo para se protegerem melhor das chuvas e que que $21 \%$ dos estudantes reconhecem a relevância da previsão para os agricultores (Fig. 10).

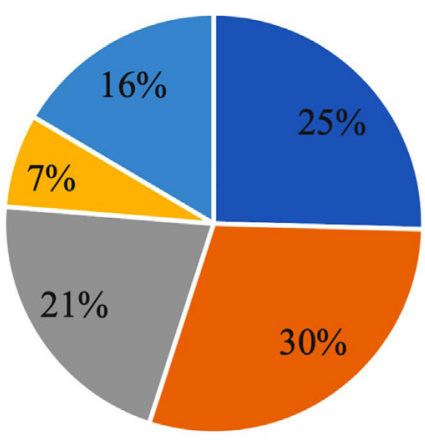

\section{- Praticar Esporte \\ - Sair de casa protegido \\ - Realiza Plantio \\ - Deixa de ir para Aula \\ - Alagamento da Rua}

Figura 10 - Relevância da previsão de tempo para a sociedade (concepção dos estudantes).

\section{Considerações Finais}

Considerando-se a importância do processo de ensino-aprendizagem dos conteúdos de climatologia esse estudo trouxe à luz as percepções de estudantes e professores do ensino fundamental sobre as práticas pedagógicas adotadas e sobre a importância desses conteúdos no cotidiano de três escolas públicas do município de Maracanaú no Ceará.

Assim, a congruência entre as respostas dos estudantes e dos professores indicaram que o uso de metodologias ativas mais utilizada em sala de aula, em particular nas aulas de climatologia, foi a atividade baseada no trabalho em equipe, deixando-se em segunda nível de importância as atividades com jogos, vídeos, situações desafiadoras e projetos interdisciplinares.

Ressalta-se que, através das análises dos resultados obtidos, observa-se a necessidade de um diálogo positivo entre os professores dessa região sobre o uso de metodologias ativas em sala de aula, e em particular nas aulas de climatologia, tendo como desafio sensibilizar e incentivar o uso destas estratégias na reelaboração de práticas inovadoras que podem obter sucesso no processo de ensinoaprendizagem desses conteúdos.

Por fim, considera-se relevante instigar estudantes e professores a perceberem a importância das discussões interdisciplinares dos conteúdos ministrados nas aulas de climatologia, por meio da aplicação de metodologias ativas que promovam atividades contextualizadas, e com o apoio de tecnologias digitais (aplicativos e outras), que busquem proporcionar a melhoraria do processo de ensino-aprendizagem destes conteúdos.

\section{Referências}

ALMEIDA, R.G.; CAVALCANTE, A.M.B. SILVA, E.M. Impactos das mudanças climáticas no bioma Caatinga na percepção dos professores da rede pública municipal de General Sampaio - Ceará. Revista Brasileira de Meteorologia, v. 35, n. 3, p. 397-405, 2020. 
ALVES, J.M.B.; REPELLI, C.A. A variabilidade pluviométrica no setor Norte do Nordeste e os eventos El Niño/Oscilação Sul (ENOS). Revista Brasileira de Meteorologia, v. 7, n. 2, p. 583-592, 1992.

AYOADE, J.O. Introdução a Climatologia Para os Trópicos. Tradução de Maria Juraci Zani dos Santos. $4^{a}$ ed. Rio de Janeiro: Bertrand Brasil, 332 p., 1996.

BACICH, L.; MORAN, J. (Orgs.). Metodologias Ativas Para Uma Educação Inovadora: Uma Abordagem TeóricoPrática. Porto Alegre: Penso, 238 p., 2018.

BACICH, L.; TANZI NETO, A.; TREVISANI, F.M. (orgs.). Ensino Híbrido: Personalização e Tecnologia na Educação. Porto Alegre: Penso, 270 p., 2015.

BRASIL. Base Nacional Comum Curricular. Brasília: Ministério da Educação, 468 p., 2017.

BRASIL. Parâmetros Curriculares Nacionais: Geografia. Brasília: Ministério da Educação/Secretaria de Educação Fundamental, 1998.

CALLAI, H.C. A educação geográfica na formação docente: convergências e tensões. In: SANTOS, L.L.C.P.; LEAL, L.F.V.; PEREIRA, J.E.D.; DALBEN, A.I.L.F. (orgs.). Convergências e Tensões no Campo da Formação e do Trabalho Docente. Coleção Didática e Prática de Ensino. Belo Horizonte: Autêntica, 412 p., 2010.

CASTELLAR, S.M.V. Metodologias Ativas: Introdução. São Paulo: FTD, 2016.

CEARÁ. Documento de Referência Curricular Nacional. Fortaleza: Secretária de Educação do Estado do Ceará, 2019.

FERNANDES, A.D.S.A.; MATSUKURA, T.S.; LUSSI, I.A.O.; FERIGATO, S.H.; MORATO, G.G. Reflexões sobre a atenção psicossocial no campo da saúde mental infantojuvenil. Cadernos Brasileiros de Terapia Ocupacional, v. 28, n. 2, p. 725-740, 2020.

FORTUNA, D. As abordagens da climatologia nas aulas de geografia do ensino fundamental (segundo segmento): Primeiras impressões. In: $4^{\circ}$ Seminário de Pesquisa do Instituto de Ciências da Sociedade e Desenvolvimento Regional, Universidade Federal Fluminense, Campos dos Goytacazes, p. 10, 2010.

KIMURA, S. Geografia no Ensino Básico: Questões e Propostas. São Paulo: Cortez, 2008.

MASETTO, M.T. Mediação pedagógica e o uso da tecnologia. In: MORAN, J.M.; MASETTO, M.T.; BEHRENS, M.A. (eds.) Novas Tecnologias e Mediação Pedagógica. Campinas: Papirus, p. 133-173, 2000.

MARENGO, J.A. Mudanças Climáticas Globais e seus Efeitos sobre a Biodiversidade. Brasília: MMA, 2006.

MELO, D.M. Aprendizagem de Climatologia em Geografia no Ensino Médio Fundamentada na Teoria de Ausubel. Dissertação de Mestrado em Geografia, Centro de Filosofia e Ciências Humanas, Universidade Federal de Santa Catarina, Florianópolis, 119 p., 2015.

MENEGUZZO, I.S.; MENEGUZZO, P.I. Os conteúdos de climatologia nos livros didáticos de geografia do $6^{\circ}$ ano do ensino fundamental. Revista Didática Sistêmica, v. 12, n. 1, p. 55-63, 2010.

MINAYO, M.C.S. O Desafio do Conhecimento: Pesquisa Qualitativa em Saúde. 14 a ed. São Paulo: Hucitec, 2014.

SANT'ANNA NETO, J.L. História da climatologia no Brasil: Gênese e paradigma do clima como fenômeno geográfico. In: Cadernos Geográficos n. 7, Trindade: Editora UFSM, 115 p., 2004.

IPCC. Relatório Especial do Painel Intergovernamental sobre Mudanças Climáticas. Disponível em https://library.wmo. int/doc_num.php?explnum_id=10072, acesso em 8 nov. 2019.

SILVA, E.M.; FREITAS, F.C.C.; BARRETO NETO, L.R.; GIRÃO, A.F.; GARCIA, C.A.P.; PINHO, L.U.; CATANHO, P.A.G. A Importância do ensino de climatologia nas ações de defesa civil em regiões de vulnerabilidade socioeconômica de Fortaleza/CE. Revista Brasileira de Meteorologia, v. 34, n. 3, p. 369-378, 2019.

SILVA. E.M.; ALBUQUERQUE, K.K.F.; ALVES, J.M.B.; MELO, F.C.B. O conhecimento sobre sismos e mudanças climáticas como proposta pedagógica: Estudo de caso em uma escola pública de Fortaleza/CE. Revista Brasileira de Meteorologia, v. 36, n. 3, p. 529-666, 2021.

ZAVATTINI, J.A. O paradigma da análise rítmica e a climatologia geográfica brasileira. Revista Geografia, v. 25, n. 3, p. $25-43,2000$.

License information: This is an open-access article distributed under the terms of the Creative Commons Attribution License (type CC-BY), which permits unrestricted use, distribution and reproduction in any medium, provided the original article is properly cited. 